\title{
Radio-induced malignancies after breast cancer postoperative radiotherapy in patients with Li-Fraumeni syndrome
}

\author{
Steve Heymann ${ }^{1 *}$, Suzette Delaloge ${ }^{2}$, Arslane Rahal $^{2}$, Olivier Caron ${ }^{3}$, Thierry Frebourg ${ }^{4}$, Lise Barreau ${ }^{5}$, \\ Corinne Pachet ${ }^{5}$, Marie-Christine Mathieu ${ }^{6}$, Hugo Marsiglia ${ }^{1,7}$, Céline Bourgier $^{1}$
}

\begin{abstract}
Background: There are no specific recommendations for the management of breast cancer patients with germline p53 mutations, an exceptional genetic condition, particularly regarding postoperative radiotherapy. Preclinical data suggested that p53 mutations conferred enhanced radiosensitivity in vitro and in vivo and the few clinical observations showed that Li-Fraumeni families were at a higher risk of secondary radio-induced malignancies.

Methods: We reviewed a cohort of patients with germ-line p53 mutations who had been treated for breast cancer as the first tumor event. We assessed their outcome and the incidence of secondary radio-induced malignancies.

Results: Among 47 documented Li-Fraumeni families treated from 1997 to 2007 at the Institut Gustave Roussy, 8 patients had been diagnosed with breast cancer as the first tumor event. Three patients had undergone conservative breast surgery followed by postoperative radiotherapy and five patients had undergone a mastectomy ( 3 with postoperative radiotherapy). Thus, 6/8 patients had received postoperative radiotherapy. Median follow-up was 6 years. Median age at the diagnosis of the primary breast cancer was 30 years. The histological characteristics were as follows: intraductal carcinoma in situ $(n=3)$, invasive ductal carcinoma $(n=4)$ and a phyllodes tumor $(n=1)$. Among the 6 patients who had received adjuvant radiotherapy, the following events had occurred: 3 ipsilateral breast recurrences, 3 contralateral breast cancers, 2 radio-induced cancers, and 3 new primaries (1 of which was an in-field thyroid cancer with atypical histology). In contrast, only one event had occurred (a contralateral breast cancer) among patients who had not received radiation therapy.
\end{abstract}

Conclusions: These observations could argue in favor of bilateral mastectomy and the avoidance of radiotherapy.

\section{Background}

Li-Fraumeni syndrome (LFS) is a rare disorder that considerably increases the risk of developing several types of cancer, particularly in children and young adults. The first observations were described by $\mathrm{Li}$ and Fraumeni in 1969 [1]. LFS is inherited in an autosomal dominant pattern with the frequent occurrence of soft tissue/bone sarcoma, breast cancer, leukemia, brain tumors and other cancers (melanoma, colon cancer, pancreatic cancer, adrenocortical carcinoma) [1,2]. Since then, several reports of affected families have contributed to a more precise definition of the Li Fraumeni syndrome [3].

\footnotetext{
* Correspondence: steve.heymann@igr.fr

'Department of Radiation Oncology, Institut Gustave Roussy, Villejuif, France Full list of author information is available at the end of the article
}

Germ-line TP53 gene mutations are mainly reported in LFS and approximately 250 distinct germ-line TP53 mutations have been described in the literature [4]. A TP53 mutation database has been established http:// www-p53.iarc.fr/[5]. Mutations in the CHEK2 gene have also been reported in a few LFS and Li Fraumeni-like syndrome (LFL) families [6-8]. Wild-type p53 was identified as the first tumor suppressor gene. It is at the crossroads of the network of signaling pathways involved in the elimination and inhibition of abnormal cell proliferation designed to prevent neoplastic development $[9,10]$. Many transcriptional targets of wild-type p53 have been implicated: (i) in cell cycle inhibition by maintaining cells in the $G 2$ cell cycle arrest, for example, the cyclin-dependent kinase inhibitor $\mathrm{p} 21^{\mathrm{Waf}}$, 
14-3-3sigma $(\sigma)$; (ii) in the regulation of apoptosis through the induction of pro-apoptotic proteins such as Bax, Apaf 1, PUMA, p53AIP1, PIDD and NOXA; (iii) in DNA repair; (iv) in angiogenesis and in metastasis inhibition [11-13]. p53 gene inactivation is essentially due to small mutations which lead to either the expression of a mutant protein ( $90 \%$ of cases) or the absence of protein expression (10\% of cases). Here, we attempted to assess the incidence of radio-induced malignancies in a prospective cohort of families with germ-line p53 mutations, focusing on breast cancer occurring as the first malignancy.

\section{Methods}

We conducted a search of the genetic screening database at the Institut Gustave Roussy (Villejuif) for "female AND breast cancer AND mutation of TP53" from 1997 to 2007. Clinical, pathological, and treatment characteristics were assessed and the analysis was performed in February 2010. A loco-regional relapse was defined as an ipsilateral relapse in either the breast or lymph nodebearing areas (axillary, internal mammary, supra-clavicular) or both occurring since the date of the diagnosis. Contralateral breast cancer was either ductal carcinoma in situ (DCIS) or invasive carcinoma. Distant disease was defined as breast carcinoma recurrences that were not in the contralateral breast nor in loco-regional areas. Second primaries were recorded in the database.

\section{Results}

Among 47 families with either LFS or LFL syndrome, eight patients were recorded as having a breast cancer as the first malignancy. The median follow-up was 6 years [2-13]. Median age was 30 years [22-48]. Among those 8 patients, 6 had received loco-regional radiation therapy. After a median follow-up of 6 years since the initial diagnosis [2-13], 3 ipsilateral breast relapses and 4 contralateral breast cancers had occurred and 2 radioinduced cancers (one chest wall angiosarcoma and one breast histiocytofibrosarcoma). One papillary thyroid carcinoma had also developed inside the radiation field, which was considered as a new primary rather than a radio-induced malignancy because of the two years of latency. Two other primaries had also occurred: a buttock liposarcoma and an ethmoidal leiomyosarcoma. Two patients had developed metastases from the primary breast carcinoma and one patient had died of metastatic disease.

\section{Patient 1}

A 27 year-old woman with a familial history of LFS had presented with a $35 \mathrm{~mm}$ DCIS of the left breast that had been treated by a radical mastectomy and axillary clearance in 1999. She had no evidence of a relapse.

\section{Patient 2}

A 32 year-old woman with a familial history of LFS had presented with a right breast cancer (Scarff and Bloom and Richardson (SBR) grade 1 invasive ductal carcinoma (IDC), pT1N0, ER+, PR+, HER2-) that had been treated by a radical mastectomy and Tamoxifen in 2007. One year after the initiation of Tamoxifen, a contralateral breast cancer (CBC) had occurred (DCIS) that had been treated by a radical mastectomy.

\section{Patient 3}

A 22 year-old woman with a familial history of multiple breast cancers had presented in 2005 with an IDC of the right breast (cT2N1, ER+, PR+, HER2+) that had been treated with neo-adjuvant chemotherapy and traztuzumab. A radical mastectomy and an axillary dissection $(1 \mathrm{~N}+/ 25)$ had been performed followed by loco-regional radiotherapy to the chest wall, internal mammary and supraclavicular nodes, endocrine therapy and a prophylactic contralateral mastectomy.

\section{Patient 4}

A 32 year-old woman without any familial history of cancer had presented with an IDC of the right breast (SBR grade $2 \mathrm{~T} 1 \mathrm{~N} 1 \mathrm{ER}+, \mathrm{PR}+, \mathrm{Her} 2+$ ). She had been treated by a radical mastectomy followed by chemotherapy with traztuzumab, loco-regional irradiation (chest wall, internal mammary and supraclavicular nodes) and Tamoxifen. Before completion of traztuzumab, i.e. 8 months after completion of radiotherapy, a CBC had been diagnosed (left axillary IDC, ER+, PR+, HER2+) that had been treated by a lumpectomy including a sentinel lymph node biopsy and chemotherapy with traztuzumab. The p53 mutation had been diagnosed during chemotherapy. Postoperative radiotherapy had therefore been cancelled and replaced by a mastectomy.

\section{Patient 5}

A 22 year-old woman without any familial history of cancer had presented with a right breast phyllodes tumor in 1997. Conservative breast surgery had been performed followed by adjuvant radiotherapy delivered to the whole breast. In 2001, she had developed a buttock liposarcoma and then a CBC (SBR grade 2 IDC) in 2004 that had been treated by conservative surgery followed by radiotherapy to the breast, internal mammary and supraclavicular nodes. An ipsilateral breast cancer (IBC) had occurred in 2008, ("in-field relapse": a $50 \mathrm{~mm}$, ER-, PR-, Her2+ mucinous carcinoma ). It had been treated by a radical mastectomy and with traztuzumab. Due to the occurrence of multiple malignancies at a very young age in this patient, she had received genetic counseling and a p53 mutation had been diagnosed. At the time of the analysis (Feb. 2010), she developed an 
ipsilateral chest wall angiosarcoma which is currently being treated with chemotherapy.

\section{Patient 6}

A 29 year-old woman with a familial history of multiple cancers had undergone conservative surgery of the right breast for an IDC (SBR grade $2 \mathrm{~T} 1 \mathrm{~N} 1, \mathrm{ER}+, \mathrm{PR}+, \mathrm{HER} 2-)$ in 1998. She had received adjuvant chemotherapy and radiotherapy. An ipsilateral, multicentric breast recurrence (IDC) had developed 10 years later (an in-field relapse of the same histologic type) and had been treated by a radical mastectomy and endocrine therapy. A TP53 mutation had been diagnosed in 2008. At the time of the analysis (Feb. 2010), a contralateral axillary recurrence was diagnosed and treated with chemotherapy.

\section{Patient 7}

A 48 year-old female had presented in 2005 with a right breast cancer (IDC) with axillary lymph node involvement and a concomitant grade 2 malignant histiocytofibroma of the left thigh measuring $8 \mathrm{~cm}$. She had a familial history of cancer ( 2 brothers with rhabdomyosarcoma, and cancers in both parents). She had received five cycles of adriamycin and ifosfamide (AI), 9 cycles of weekly paclitaxel and had undergone a mastectomy with axillary clearance for the IDC (SBR grade $3 \mathrm{ER}+, \mathrm{PR}+$, HER2-) measuring $120 \mathrm{~mm}$ with multiple vascular involvement $(\mathrm{VI})$ and $9 \mathrm{~N}+/ 16$. She had received radiotherapy to the chest wall, internal mammary and supraclavicular nodes and endocrine therapy. She had undergone surgery for the malignant histiocytofibroma of the thigh after the 5 cycles of AI.

In August 2007, she had undergone a thyroidectomy and bilateral neck and superior mediastinal lymph node dissection for a papillary carcinoma with VI, $10 \mathrm{~N}+$, followed by radioactive iodine therapy. In April 2008, she had developed a liver metastasis and had been treated with 3 lines of chemotherapy. She had progressive disease at the time of the analysis (Feb 2010).

\section{Patient 8}

A 39 year-old female diagnosed with a DCIS of the left breast had undergone a lumpectomy and had received postoperative radiotherapy and tamoxifen. In 2004, she had developed a local relapse that had been treated by a mastectomy and axillary clearance. Two tumors had been discovered: one grade 2 histiocytofibrosarcoma and $6 \mathrm{~N}+$ exhibiting IDC (ER+, PR+, HER2-). She had received adjuvant chemotherapy, radiotherapy to the chest wall, internal mammary and supraclavicular nodes and then endocrine therapy. In 2006, she had developed a grade 2 ethmoidal leiomyosarcoma that had been treated by surgery and radiotherapy. In December 2006, she had presented with a left infracapsular mass which had been diagnosed as metastasis from IDC and had been treated with chemotherapy. She had developed cerebral metastasis in September 2007 and pleural metastasis in December of the same year. She had died at the end of 2008 of disease progression. Her 18 year-old daughter has 2 sarcomas.

\section{Genomic analysis \\ TP53 analysis}

The 11 exons of TP53 and intron-exon boundaries were thoroughly analyzed by direct sequencing after genomic DNA amplification. Genomic rearrangements were sought by Quantitative Multiplex Polymerase chain reaction of Short Fragments (QMPSF), as described elsewhere [14].

We screened the mutations on the IARC website http://www-p53.iarc.fr. Table 1 lists the type of germline p53 mutation for each patient. The majority of the mutations were missense mutations resulting in abnormal protein function. Patients 1 and 8 had a splicing mutation. The splicing mutation in patient 1 has already been described as a germ-line mutation in 8 LFS families and the mutation in patient 8 , which induces buried DNA-binding function, has already been described in 2 LFS families.

\section{Discussion}

To our knowledge, this is the first report on breast cancer as the first tumor in LFS, without any previous cytotoxic therapy. A large retrospective cohort study assessed the outcomes of long-term survivors after cancer treatments in childhood. The results were alarming because they suggested that chemotherapy and ionizing radiation exposure increased the incidence of second malignancies. More specifically, radiation exposure among TP53 mutation carriers seemed to increase second cancers [15]. Other small cohort studies have suggested a similar outcome [16-19].

No specific clinical or histological feature of breast cancer occurring as a first event has been described in other series. A young age is commonly associated with an aggressive breast cancer phenotype [20,21]. Furthermore, a young age implied breast cancer mutations, such as BRCA mutations. In BRCA1 mutation carriers, breast cancers mostly exhibited a basal-like molecular phenotype [22].

Besides the histological characteristics of breast cancers associated with a young age, a young age has also been reported to be a poor prognostic factor for distant metastases $[23,24]$. Nonetheless, in the present study with a median follow-up of 6 years, only $2 / 8$ patients had developed distant metastases. Indeed, our patients had mostly developed either local recurrences or contralateral breast cancer. 
Table 1 Patient characteristics, outcome and genetic information

\begin{tabular}{|c|c|c|c|c|c|c|c|c|}
\hline & 1 & 2 & 3 & 4 & 5 & 6 & 7 & 8 \\
\hline Age & 27 & 32 & 22 & 32 & 22 & 29 & 48 & 39 \\
\hline Histology & DCIS & IDC and DCIS & IDC & IDC & $\begin{array}{l}\text { Phyllodes } \\
\text { sarcoma }\end{array}$ & IDC & IDC & DCIS \\
\hline Grade & NA & 1 & NA & 2 & NA & 2 & 3 & NA \\
\hline Hormonal receptor & UN & pos & pos & pos & NA & pos & pos & pos \\
\hline HER2 overexpression & NA & neg & pos & pos & NA & neg & neg & NA \\
\hline TNM & TisNOMO & T1NOMO & T2N1M0 & T1N1M0 & TxNOMO & T1N1M0 & T4N1M0 & TisNOMO \\
\hline Adjuvant Radiotherapy & No & No & Yes & Yes & Yes & Yes & Yes & Yes \\
\hline Local relapse & No & No & No & No & Yes & Yes & No & Yes \\
\hline $\begin{array}{l}\text { Contralateral breast } \\
\text { cancer }\end{array}$ & No & Yes & No & Yes & Yes & Yes & No & No \\
\hline Radio induced tumors & No & No & No & No & Yes & No & ${ }^{*}$ & Yes \\
\hline $\begin{array}{l}\text { New primary outside RT } \\
\text { field }\end{array}$ & No & No & No & No & Yes & No & No & Yes \\
\hline $\begin{array}{l}\text { Codon } \\
\text { Mutation }\end{array}$ & $\begin{array}{l}\text { C.375G }>C \\
\text { exon } 4 \\
\text { splice site }\end{array}$ & $\begin{array}{l}c .844 C>T \\
\text { exon } 8 \\
\text { missense }\end{array}$ & $\begin{array}{l}\text { C. } 742 C>T \\
\text { exon } 7 \\
\text { missense }\end{array}$ & $\begin{array}{l}\text { c.467G }>\text { A } \\
\text { exon } 5 \\
\text { missense }\end{array}$ & $\begin{array}{c}\text { c.724T >C exon } \\
7 \\
\text { missense }\end{array}$ & $\begin{array}{l}\text { C. } 542 \mathrm{G}>\mathrm{A} \\
\text { exon } 5 \\
\text { missense }\end{array}$ & $\begin{array}{l}\text { c. } 524 \mathrm{G}>\mathrm{A} \\
\text { exon } 5 \\
\text { missense }\end{array}$ & $\begin{array}{c}\text { c. } 673-2 A>C \\
\text { intron } 6 \\
\text { splice site }\end{array}$ \\
\hline
\end{tabular}

DCIS: ductal carcinoma in situ; IDC: invasive ductal carcinoma; UN unknown; NA: non applicable; * in field tumor with atypical histology

In an overall population of patients treated for a breast cancer, the risk of loco-regional relapse after breast surgery and postoperative radiotherapy is commonly reported to be $1 \%$ per year. A young age is the main prognostic factor for loco-regional relapses with a first peak before the first 2-3 years after the completion of treatment followed by a decreasing risk over time [20]. Even though the cohort under study was small, an ipsilateral breast relapse ("in-field relapse") had occurred in $3 / 8$ patients (in 2 , ten years after the initial diagnosis). In addition, $C B C$ had occurred in 4/8 patients but one had undergone a prophylactic contralateral mastectomy.

Radio-induced cancers are usually a very rare event arising 10 years after irradiation with an incidence of less than $2 \%$ [25]. In the present cohort of LFS, a chest wall angiosarcoma, a malignant histiocytofibroma and a papillary thyroid carcinoma had developed inside the irradiated volumes in $3 / 8$ patients.

Experimental data highlighted the role of ionizing radiation stress in human cells harboring heterozygous germ-line p53 mutations, leading to a defective cell cycle arrest in G1/S and/or a lesser apoptotic response of lymphocytes [26]. All these cellular features may promote radiosensitization and thus carcinogenesis [26]. In addition to these in vitro results, in vivo studies showed that ionizing radiation accelerated the emergence of solid tumors in Trp53 heterozygous null mice [27]. To reinforce experimental data, a few, albeit, very small retrospective cohort studies have reported a higher risk of developing a radiation-induced malignancy among TP53 mutation carriers [16-19].
The events described here are probably the result of the sum of the effects of the genetic background on both the risk of new primaries, especially within the breast, and the risk of radiation-induced carcinogenesis. Recent data highlighted the importance of a familial history of cancer or multiple primary tumours $(6 / 8$ patients in our cohort) $[2,28]$. Thus, we strongly believe that patients with early onset breast cancer should be tested for TP53 mutation according to updated Chompret criteria [28].

\section{Conclusion}

If a germ-line mutation is detected, we recommend that it be taken into account for decision-making concerning local treatment: 1. Adjuvant radiation therapy for localized breast cancer should be extensively discussed and prohibited whenever the risk/benefit ratio is doubtful. 2 . Both a mastectomy of the cancer-bearing breast and a contralateral prophylactic mastectomy (with immediate reconstruction, as frequently as possible) should be advised and discussed with the patient, as is the case for BRCA1/2 mutation carriers, with the additional advantage of potentially avoiding radiation therapy if conservative treatment is avoided.

\section{List of abbreviations}

LFS: Li-Fraumeni syndrome; LFL: Li-Fraumeni-like syndrome; IDC: invasive ductal carcinoma; DCIS: ductal carcinoma in situ; SBR: Scarff Bloom Richardson; ER: estrogen receptor; PR: progesterone receptor; $\mathrm{CBC}$ : contralateral breast cancer; IBC: ipsilateral breast cancer; 
AI: adriamycin ifosfamide; VI: vascular involvement; QMPSF: Quantitative Multiplex Polymerase chain reaction of Short Fragments.

\section{Acknowledgements}

The authors thank Lorna Saint Ange for editing. Meeting presentation: 2009 ASCO Annual Meeting. J Clin Oncol 27, 2009 (May 20 Suppl; abstract 11043).

\section{Author details}

'Department of Radiation Oncology, Institut Gustave Roussy, Villejuif, France. ${ }^{2}$ Department of Breast Oncology, Institut Gustave Roussy, Villejuif, France. ${ }^{3}$ Department of Genetics Counseling, Institut Gustave Roussy, Villejuif, France. ${ }^{4}$ Genetic Department, Academic Hospital, Rouen, France. ${ }^{5}$ Department of Breast Surgery, Institut Gustave Roussy, Villejuif, France. ${ }^{6}$ Department of Pathology, Institut Gustave Roussy, Villejuif, France. ${ }^{7}$ University of Florence, Italy.

\section{Authors' contributions}

SH, SD, and AR reviewed the medical files. OC and TF carried out the molecular genetic studies. SH, SD, CB, HM drafted the manuscript. CB and SD: conception, design. MCM, LB and CP participated in the design of the study. All authors read and approved the final manuscript.

\section{Competing interests}

The authors declare that they have no competing interests.

Received: 22 June 2010 Accepted: 8 November 2010 Published: 8 November 2010

\section{References}

1. Li FP, Fraumeni JF Jr: Soft-tissue sarcomas, breast cancer, and other neoplasms. A familial syndrome? Ann Intern Med 1969, 71:747-752.

2. Gonzalez KD, Noltner KA, Buzin CH, et al: Beyond Li Fraumeni Syndrome: clinical characteristics of families with p53 germline mutations. J Clin Oncol 2009, 27:1250-1256.

3. Li FP, Fraumeni JF Jr, Mulvihill JJ, et al: A cancer family syndrome in twenty-four kindreds. Cancer Res 1988, 48:5358-5362.

4. Varley JM: Germline TP53 mutations and Li-Fraumeni syndrome. Hum Mutat 2003, 21:313-320.

5. Olivier $\mathrm{M}$, Goldgar DE, Sodha N, et al: Li-Fraumeni and related syndromes: correlation between tumor type, family structure, and TP53 genotype. Cancer Res 2003, 63:6643-6650.

6. Lee SB, Kim SH, Bell DW, et al: Destabilization of CHK2 by a missense mutation associated with Li-Fraumeni Syndrome. Cancer Res 2001, 61:8062-8067.

7. Varley J: TP53, hChk2, and the Li-Fraumeni syndrome. Methods Mol Biol 2003, 222:117-129.

8. Varley J, Haber DA: Familial breast cancer and the hCHK2 1100delC mutation: assessing cancer risk. Breast Cancer Res 2003, 5:123-125.

9. Vogelstein B, Lane D, Levine AJ: Surfing the p53 network. Nature 2000, 408:307-310.

10. Vousden KH: Activation of the $\mathrm{p} 53$ tumor suppressor protein. Biochim Biophys Acta 2002, 1602:47-59.

11. Gasco M, Shami S, Crook T: The p53 pathway in breast cancer. Breast Cancer Res 2002, 4:70-76.

12. Wang $\mathrm{QE}$, Zhu $\mathrm{Q}$, Wani $\mathrm{MA}$, et al: Tumor suppressor $\mathrm{p} 53$ dependent recruitment of nucleotide excision repair factors XPC and TFIIH to DNA damage. DNA Repair (Amst) 2003, 2:483-499.

13. Fei P, El-Deiry WS: P53 and radiation responses. Oncogene 2003, 22:5774-5783

14. Bougeard $G$, Brugieres $L$, Chompret $A$, et al: Screening for TP53 rearrangements in families with the Li-Fraumeni syndrome reveals a complete deletion of the TP53 gene. Oncogene 2003, 22:840-846.

15. Kony SJ, de Vathaire F, Chompret A, et al: Radiation and genetic factors in the risk of second malignant neoplasms after a first cancer in childhood. Lancet 1997, 350:91-95.

16. Hisada M, Garber JE, Fung CY, et al: Multiple primary cancers in families with Li-Fraumeni syndrome. J Natl Cancer Inst 1998, 90:606-611.
17. Nutting C, Camplejohn RS, Gilchrist R, et al: A patient with 17 primary tumours and a germ line mutation in TP53: tumour induction by adjuvant therapy? Clin Oncol (R Coll Radiol) 2000, 12:300-304.

18. Limacher JM, Frebourg T, Natarajan-Ame S, et al: Two metachronous tumors in the radiotherapy fields of a patient with Li-Fraumeni syndrome. Int J Cancer 2001, 96:238-242.

19. Salmon A, Amikam D, Sodha N, et al: Rapid development of postradiotherapy sarcoma and breast cancer in a patient with a novel germline 'de-novo' TP53 mutation. Clin Oncol (R Coll Radiol) 2007 19:490-493.

20. Bollet MA, Sigal-Zafrani $B$, Mazeau $V$, et al: Age remains the first prognostic factor for loco-regional breast cancer recurrence in young ( < 40 years) women treated with breast conserving surgery first. Radiother Oncol 2007, 82:272-280.

21. Prise en charge du cancer du sein infiltrant de la femme non ménopausée. Oncologie 2009, 11:507-532.

22. Livasy CA, Karaca G, Nanda R, et al: Phenotypic evaluation of the basallike subtype of invasive breast carcinoma. Mod Pathol 2006, 19:264-271.

23. Veronesi $U$, Marubini $E$, Del Vecchio $M$, et al: Local recurrences and distant metastases after conservative breast cancer treatments: partly independent events. J Natl Cancer Inst 1995, 87:19-27.

24. Fowble BL, Schultz DJ, Overmoyer B, et al: The influence of young age on outcome in early stage breast cancer. Int J Radiat Oncol Biol Phys 1994 30:23-33.

25. Rubino C, de Vathaire F, Shamsaldin A, et al: Radiation dose, chemotherapy, hormonal treatment and risk of second cancer after breast cancer treatment. Br J Cancer 2003, 89:840-846.

26. Delia D, Goi K, Mizutani S, et al: Dissociation between cell cycle arrest and apoptosis can occur in Li-Fraumeni cells heterozygous for p53 gene mutations. Oncogene 1997, 14:2137-2147.

27. Mitchel RE, Jackson JS, Carlisle SM: Upper dose thresholds for radiationinduced adaptive response against cancer in high-dose-exposed, cancerprone, radiation-sensitive Trp53 heterozygous mice. Radiat Res 2004, 162:20-30

28. Tinat J, Bougeard G, Baert-Desurmont S, et al: 2009 version of the Chompret criteria for Li Fraumeni syndrome. J Clin Oncol 2009, 27: e108-109, author reply e110.

doi:10.1186/1748-717X-5-104

Cite this article as: Heymann et al:: Radio-induced malignancies after breast cancer postoperative radiotherapy in patients with Li-Fraumeni syndrome. Radiation Oncology 2010 5:104.

\section{Submit your next manuscript to BioMed Central and take full advantage of:}

- Convenient online submission

- Thorough peer review

- No space constraints or color figure charges

- Immediate publication on acceptance

- Inclusion in PubMed, CAS, Scopus and Google Scholar

- Research which is freely available for redistribution
Biomed Centra 